\title{
Job Satisfaction of the Factory Workers at the Manufacturing Plant: A Case Study
}

\author{
Nushrath Najimuddin, Sachith Abeysundara \\ Department of Statistics and Computer Science, Faculty of Science, University of Peradeniya, Peradeniya, Sri Lanka \\ Email: nushrath23@gmail.com, sachith.me@gmail.com
}

How to cite this paper: Najimuddin, N. and Abeysundara, S. (2019) Job Satisfaction of the Factory Workers at the Manufacturing Plant: A Case Study. Open Access Library Journal, 6: e5312.

https://doi.org/10.4236/oalib.1105312

Received: March 6, 2019

Accepted: April 9, 2019

Published: April 12, 2019

Copyright $\odot 2019$ by author(s) and Open Access Library Inc.

This work is licensed under the Creative Commons Attribution International License (CC BY 4.0).

http://creativecommons.org/licenses/by/4.0/

(c) (i) Open Access

\begin{abstract}
The aim of this study is to evaluate factory workers' job satisfaction in a manufacturing plant in Sri Lanka. A sample of 180 employees from a study population of 846 was taken. Stratified Random Sampling method was used as the sampling technique. The tool used for the data collection is a questionnaire which was designed covering all the aspects related to the job satisfaction of the factory workers in the manufacturing plant. The analysis was carried out using the statistical software SPSS version 20.0. Demographic variables which are associated with the overall job satisfaction at $5 \%$ level of significance and the four factors which were identified from the factor analysis process were used for the model building procedure. Ordinal regression model was developed which includes the factors affecting job satisfaction. For the variable selection procedure, the forward selection method was applied. Statistically, "Work arrangements in the workplace" and "Family issues of the workers" were the most influencing factors to job satisfaction and "Gender", "The distance employees travel" and "Mode of transportation of employees" were the demographic factors associated with the level of job satisfaction.
\end{abstract}

\section{Subject Areas}

Case Studies and Management Information Systems, Human Resource Management, Statistics

\section{Keywords}

Job Satisfaction, Factory Workers, Survey

\section{Background}

\subsection{Introduction}

Employees are an organization's main resource. In the event that employees are 
satisfied with their employment, they would produce an extraordinary quality execution that enables an organization to develop and achieve the accomplishment with changing economic condition. Therefore, rival, more knowledgeable and well-satisfied workforce is a benefit for an organization.

A common definition of job satisfaction is "a pleasurable or positive emotional state resulting from the appraisal of one's job or job experiences" [1]. It is also defined as "a set of favorable or unfavorable feelings and emotions which employees view with their work" [2]. According to [3], job satisfaction is an employee's feeling of accomplishment and success on the job. It is commonly considered to be directly connected to efficiency and in addition to individual prosperity. Job satisfaction indicates doing an employment that one enjoys with enthusiastic and being remunerated for one's endeavors. Job satisfaction is the key factor that prompts to acknowledgement, income, promotion and the accomplishment of different goals that lead to a feeling of satisfaction [3]. Job satisfaction is a component of life satisfaction, and then it should predict life satisfaction over some period of time [4].

A researcher examined characteristics of job satisfaction such as culture, leadership communication, commitment, job content, training, rewards and recognition opportunities, teamwork, superior subordinate relationship and delegation, at Badarpur thermal power station, NTPC Ltd. The results produced through the analysis have shown that team work, commitment, culture, communication and training are the most important factors which have led to job satisfaction, and delegation, job design, opportunities, rewards and leadership are the factors which need to be work on [5]. The level of job satisfaction of Caucasian and Hispanic American Accounting Professionals was carried out by analyzing the relationship between these job satisfaction factors and different demographic factors, such as profession, frame size, certification, age, sex, race, advanced degrees and parent education. The results show that there are differences between what respondents feel influences their level of satisfaction on the job. Employers need to be cognizant of the factors that impact employee satisfaction and implement corporate policies that can enhance employee performance [6].

Three important attributes of job satisfaction are discussed as follows. Firstly, organizations ought to be guided by human values where organizations will be arranged towards approaching workers with respect and in a fairly manner as a high level of job satisfaction may be a sign of a good emotional and mental state of employees. Second, the functioning of the organization will depend on the workers' level of job satisfaction which may change according to the workers' behaviors. Third, job satisfaction may serve as indicators of organizational activities [7].

Employee absenteeism has become a serious issue including additional costs for companies. Therefore, the employers are in a responsibility to reduce it to its minimum. Increasing the level of employees' satisfaction would be the effective way to reduce absenteeism and that would be a factor worth paying attentions to 
absenteeism, since it would be controllable by the managers, unlike other factors such as sick, immediate family member death, etc. An employer could be implicitly encouraging absenteeism by enforcing company policies [8] [9] [10].

For comparison of identified factors across social and demographic factors Kruskal-Wallis test and Mann-Whitney U test were used in the research carried out to identify job satisfaction factors of PTCL employees and the dimension of data was reduced using factor analysis and they are empowerment, salary and benefits, environment, boss attitude, peer relationship, workload, rules and regulation and promotions [11]. Another research was conducted in the ready-made garments (RMG) industry of Bangladesh in which the objectives of the study were to check the job environment of RMG industry, to examine the marital status of the workers, to examine the expected salary, to determine the behavior of boss to the worker and to identify the employee's job satisfaction affecting job enhancement of the RMG sector in Bangladesh. Bivariate analysis, Logistic regression analysis and Percentage analysis are the primary tools used for the data analysis [12].

According to Department of Census and Statistics, Labour Force Survey, Annual Report (2017), 20\% of Sri Lanka's labour force is in the industry group of manufacturing which is considered to be the second largest labour force in Sri Lanka. The present research is conducted in one of the private leading manufacturers in Sri Lanka. The organization name has not been uncovered since the survey shares some sensitive information about the representative observations on their business. The research under investigation focused on the factory workers in the manufacturing plant, since they are the primary employment category of the industry as the manufacturing plant mainly rely on the factory workers.

\subsection{Objectives of the Study}

1) Identify the level of job satisfaction of the factory workers in the manufacturing plant.

2) Identify the latent factor structure and build up a model which employee job satisfaction can be properly identified through the factors used.

3) Prioritize the factors according to their importance.

\section{Study Design and Methods}

The target population of the research was all the factory workers working in the manufacturing plant of the factory. The sample size of the study was determined using the following equation [13].

$$
n=\frac{\frac{p(1-p)}{V}}{1+\frac{\left[\frac{p(1-p)}{v}-1\right]}{N}} ; V=\left[\frac{d}{Z_{\frac{\alpha}{2}}}\right]^{2}
$$


where,

$n$-Sample size required

$N$-Number of units in the population

$p$-Estimated variance in the population

$d$-Margin of error

$Z_{\alpha / 2}$-Based on confidence interval (95\% confidence interval)

If there is a doubt about selecting the value of $\mathrm{p}$, then the best to err towards $50 \%$ as it would lead to a large sample size [13]. The population size is 846 and 0.06 was taken as the suitable margin of error.

Therefore, the target sample is,

$$
\mathrm{n}=\frac{\frac{0.5(1-0.5)}{\left(\frac{0.06}{1.96}\right)^{2}}}{\left[\frac{0.5(1-0.5)}{\left(\frac{0.06}{1.96}\right)^{2}}-1\right]}=202.996 \approx 203
$$

From the target sample, 188 factory workers responded and returned the questionnaire. From all the collected questionnaires there were 8 questionnaires which had to be considered as incomplete questionnaires. After eliminating incomplete questionnaires, 180 samples were obtained which was a response rate of $88.67 \%$.

The sampling design used was Stratified Sampling Technique in which the gender was used as the stratification variable, since the literature suggests that the variability of the job satisfaction of the employees can change based on their gender [14] [15] [16]. Then the proportional allocation method has been used to obtain the number of individuals that has to be sampled within each stratum.

A structured questionnaire was used as the data collection instrument which was designed covering all the aspects related to the job satisfaction of the factory workers in the manufacturing plant. Every single question was designed very carefully by considering the formulated objectives, selected target population, sampling method and data collection method that decided under the survey design. Mainly the questionnaire contained 3 types of variables: Demographic variables, Personal variables, Job related variables. The questionnaire was initiated with an introduction clarifying the purpose and the confidentiality of the information provided by the survey. Questions on the same variable has been clustered together to improve the ease of filling and all the questions were given in table format to reduce the messiness between the questions. Five-point likert scale questions were used to represent job related variables where 1 represents "Highly satisfied/Strongly agree" and 5 represents "Highly dissatisfied/Strongly disagree". When developing the questionnaire, the nature of the mind set and the knowledge of the respondents were taken in to consideration. Hence, the 
questionnaire was built in Sinhala and Tamil languages and questions were structured in an easier and casual way to improve its understandability.

A pilot survey was carried out before conducting the main survey in order to check the quality of the questionnaire. Initially 25 questionnaires were distributed among the factory workers to check the effectiveness of the designed questionnaire. Few modifications were done in some questions, few questions were added to the questionnaire and few questions were removed from the questionnaire. After carrying out the required modifications, another 10 developed questionnaires were distributed among the factory workers to check the quality of the modified questionnaire. No more modifications were required; hence the data was collected using the modified questionnaire. Data collection procedure for the main survey was carried out within four working days at the manufacturing plant.

\section{Results and Discussion}

Descriptive statistics were used to summarize the data. Five statements have been used in order to capture the underlying phenomenon of overall job satisfaction (Dependent variable). The Cronbach's alpha value for the scale used for overall job satisfaction is 0.805 which indicates a high level of internal consistency for the scale used. It is recommended that the scale that receive alpha score over 0.7 are considered to be reliable [17].

Mann-Whitney U test, Kruskal-Wallis test, Kendall's Tau-b and Kendall's Tau-c are the tests used to identify the demographic variables which are associated with the overall job satisfaction. Hence, 8 demographic variables (Gender of the employees, Education level of the employees, Age category of employees, Accommodation of employees, Mode of transportation of employees to reach the workplace, The distance employees travel to reach the workplace, Service level of employees in the workplace and Previous job of employees) were found to be significantly associated with overall job satisfaction at $5 \%$ level of significance.

Kaiser-Meyer-Olkin Measure of Sampling Adequacy and Bartlett's Test of Sphericity were used to test the strength among statements in order to verify whether the statements are suitable for the factor analysis process. In this study the KMO value lies between 0.7 and 0.9 and the Bartlett's Test is significant at $5 \%$ level of significance. Therefore, the results suggest that the data are appropriate for the factor analysis process [18].

The principle component method was used to identify the number of factors to be extracted from the statements. After about fourth factor the scree plot is leveled off into some extent and there is a slight bend after the seventh factor also (Figure 1). Therefore, the number of factors that have to be extracted according to Principle Component Method is seven. Those factors cumulatively account for $72.41 \%$ of the total variance. Varimax rotation was used to attain rotated solutions for the factor model. Clear pattern of the factor loadings can be 
obtained through the results and very few statements from the rotation have shown loadings lower than the cut off value of 0.4 (Table 1 ).

A factor analysis with four factors was also carried out in order to obtain a simpler factor structure compared to the model with seven factors (Figure 1). All the statements which were highly loaded to the first factor are expressing about the facilities and the working environment in the manufacturing plant ("Facilitative working environment"). The second factor includes the statements which specifies about the arrangements of the work at the workplace ("Work arrangements"). The third factor captures the statements which specifies about workers' personal issues related to their family ("Family issues"). Finally, the flexibility of the work procedure has been grouped to the fourth factor in the model ("Flexible working arrangements") (Table 2).

Ordinal regression model was developed which includes the factors affecting job satisfaction. Since the distribution of the satisfaction level suggests that the higher categories are more probable in the response category, the complementary log-log link is used as the link function [19]. Therefore, the model is known as the discrete proportional hazard model. Forward selection method was applied as the variable selection procedure.

Eight demographic variables which are associated with the overall job satisfaction at $5 \%$ level of significance and the four factors which were identified from the factor analysis process were taken as predictors for the model building procedure.

The final model suggested is as follows,

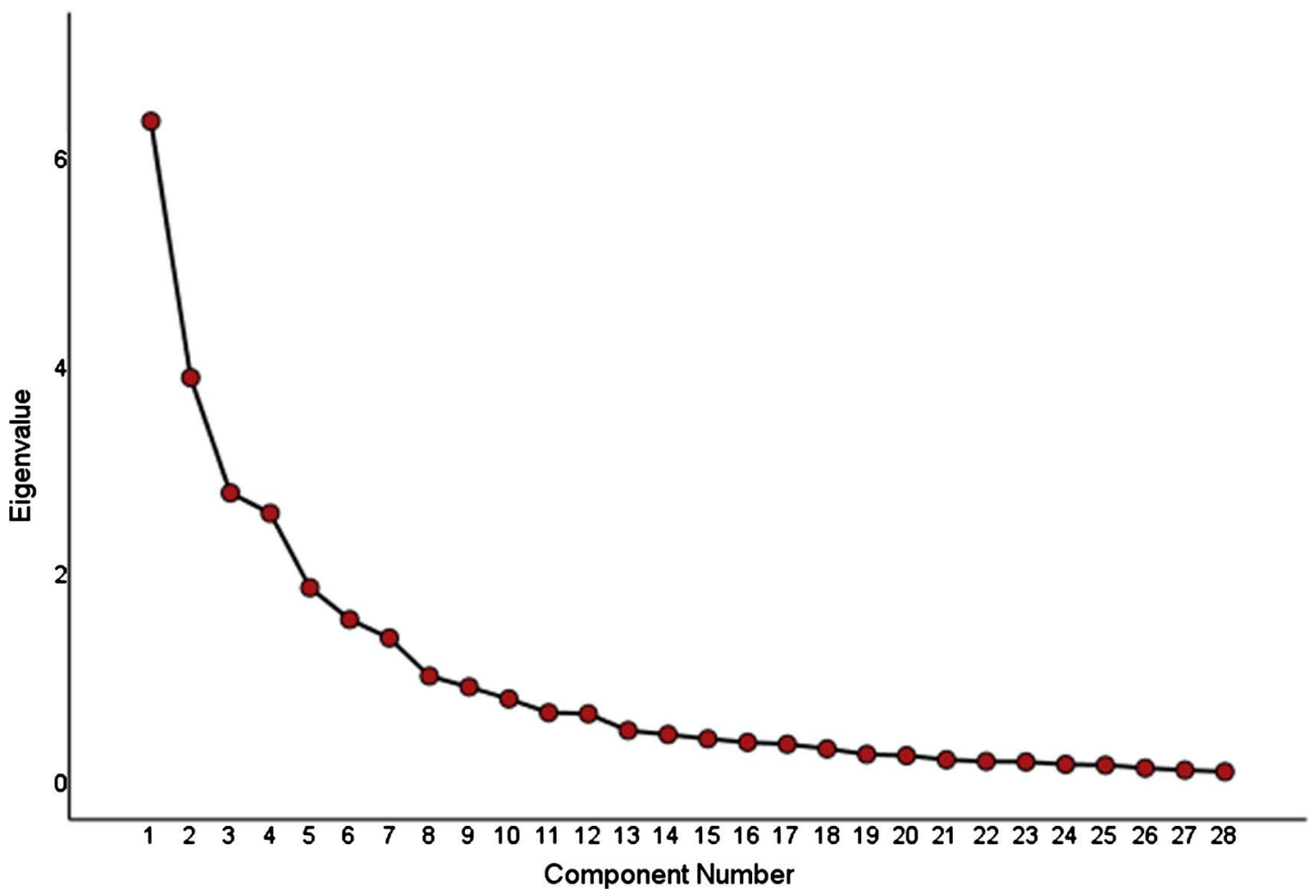

Figure 1. Scree plot. 
Table 1. Factor interpretation (Model I).

\begin{tabular}{|c|c|c|}
\hline Factor & Statements & Varimax rotated factor loadings \\
\hline \multirow{6}{*}{$\begin{array}{l}\text { Physical working environment } \\
\text { in the workplace }\end{array}$} & Sanitary facilities & 0.886 \\
\hline & Arrangement of the canteen & 0.872 \\
\hline & Safety in the working environment & 0.825 \\
\hline & Number of uniforms given & 0.820 \\
\hline & Medical services provided & 0.611 \\
\hline & Number of damages you have done within an hour & 0.609 \\
\hline \multirow[t]{4}{*}{ Family issues of the employees } & I suffer from some family problems & 0.906 \\
\hline & Too many people depend on my salary & 0.831 \\
\hline & Family issues have an adverse effect on my job & 0.815 \\
\hline & Family members push me to go for another job & 0.720 \\
\hline \multirow{6}{*}{$\begin{array}{l}\text { Company policy and administration } \\
\text { in the workplace }\end{array}$} & When my targets covered I am recognized and appreciated & 0.858 \\
\hline & I feel personally appreciated for my contributions & 0.707 \\
\hline & The current recognition system is adequate & 0.636 \\
\hline & I prefer the way my supervisor deals with me on my job & 0.603 \\
\hline & Target given within an hour & 0.470 \\
\hline & My supervisor gives me necessary feedbacks to improve my work & 0.454 \\
\hline \multirow[t]{4}{*}{ Work arrangements in the workplace } & My supervisor clearly inform me about the targets that should be covered & 0.794 \\
\hline & It gives me a great pleasure to work with my colleagues & 0.749 \\
\hline & Number of intervals per day & 0.617 \\
\hline & Duration of the intervals & 0.528 \\
\hline \multirow[t]{3}{*}{ Rules and resources in the workplace } & Company rules and regulations make me comfortable at work & 0.856 \\
\hline & I feel I am being paid a fair amount for the work I do & 0.719 \\
\hline & Condition of the machines used & 0.657 \\
\hline \multirow{2}{*}{$\begin{array}{l}\text { Work style and entertainment } \\
\text { in the workplace }\end{array}$} & Work style that has been given to your line & 0.836 \\
\hline & Entertainment events (trips and functions) & 0.684 \\
\hline \multirow[t]{2}{*}{ Work place environment } & Ventilation at the workplace & 0.803 \\
\hline & Lighting at the workplace & 0.694 \\
\hline
\end{tabular}

$$
\log \left[-\log \left(1-Q_{i j k l}\right)\right]=\alpha_{\mathrm{i}}+\beta_{j}^{\mathrm{gend}}+\beta_{k}^{\mathrm{ditr}}+\beta_{1}^{\mathrm{motr}}+\beta^{\mathrm{wkar}}+\beta^{\mathrm{fmis}}
$$

where, gend $=$ Gender of the employees; $j=1$ (Male), 2 (Female) dirt $=$ The distance employees travel to reach the workplace; $\mathrm{k}=1$ (Less than 5 $\mathrm{km}), 2(5 \mathrm{~km}$ to $10 \mathrm{~km}), 2(11 \mathrm{~km}$ to $20 \mathrm{~km}), 4$ (More than $20 \mathrm{~km}$ ) motr $=$ Mode of transportation of employees to reach the workplace; $1=1$ (By private transportation), 2 (By public transportation), 3 (By foot) wkar $=$ Work arrangements in the workplace fmis $=$ Family issues of the employees 
Table 2. Factor interpretation (Model II).

\begin{tabular}{|c|c|c|}
\hline Factor & Statements & Varimax rotated factor loadings \\
\hline \multirow{7}{*}{$\begin{array}{l}\text { Facilitative working environment } \\
\text { in the workplace }\end{array}$} & Arrangement of the canteen & 0.858 \\
\hline & Sanitary facilities & 0.830 \\
\hline & Number of uniforms given & 0.797 \\
\hline & Safety in the working environment & 0.772 \\
\hline & Number of damages you have done within an hour & 0.676 \\
\hline & Medical services provided & 0.564 \\
\hline & Condition of the machines used & 0.460 \\
\hline \multirow[t]{9}{*}{ Work arrangements in the workplace } & I prefer the way my supervisor deals with me on my job & 0.756 \\
\hline & When my targets covered I am recognized and appreciated & 0.734 \\
\hline & My supervisor gives me necessary feedbacks to improve my work & 0.726 \\
\hline & Rules and regulations practiced in the division & 0.587 \\
\hline & The current recognition system is adequate & 0.558 \\
\hline & Target given within an hour & 0.557 \\
\hline & My supervisor clearly inform me about the targets that should be covered & 0.527 \\
\hline & I feel personally appreciated for my contributions & 0.463 \\
\hline & Night shift practices of the organization & 0.446 \\
\hline \multirow[t]{4}{*}{ Family issues of the factory workers } & I suffer from some family problems & 0.834 \\
\hline & Family issues have an adverse effect on my job & 0.804 \\
\hline & Family members push me to go for another job & 0.790 \\
\hline & Too many people depend on my salary & 0.782 \\
\hline \multirow{4}{*}{$\begin{array}{l}\text { Flexible working arrangements } \\
\text { in the workplace }\end{array}$} & Number of intervals per day & 0.856 \\
\hline & Duration of the intervals & 0.775 \\
\hline & Entertainment events & 0.521 \\
\hline & I feel I am being paid a fair amount for the work I do & 0.404 \\
\hline
\end{tabular}

All the factors identified from the factor analysis procedure are highly significant (under $0.01 \%$ level of significance) in the model compared to the demographic factors (Table 3 ).

Goodness of fit tests used to measure the adequacy of the fitted model. The test of parallel lines is conducted to check the parallel regression assumption. The significance value of the test is well over the preferred $5 \%$ level of significance indicating that the model holds the proportional odds assumption (Table 4). Likelihood ratio deviance and Pearson chi-square statistics were used to measure the fitness of the model. Both tests have p-values greater than 0.05 suggesting that the fit of the model is adequate (Table 5).

After fitting the ordinal regression model to the available data, odds ratios were used to explain the strength of the association between overall job satisfaction of the factory workers and the all significant factor levels (Table 6). Odds 
Table 3. Parameter estimation.

\begin{tabular}{cccccccc}
\hline Parameter & Estimate & $\begin{array}{c}\text { Standard } \\
\text { error }\end{array}$ & Wald & $\begin{array}{c}\text { Degrees of } \\
\text { freedom }\end{array}$ & P-value & \multicolumn{2}{c}{$95 \%$ confidence interval } \\
\hline Intercept $=2$ & 3.866 & 1.329 & 8.467 & 1 & 0.004 & 1.262 & 6.470 \\
Intercept $=3$ & 6.324 & 1.365 & 21.472 & 1 & 0.000 & 3.649 & 8.999 \\
gend $=1$ & -1.828 & 0.288 & 40.157 & 1 & 0.000 & -2.393 & -1.262 \\
ditr $=1$ & 2.025 & 0.564 & 12.902 & 1 & 0.000 & 0.920 & 3.131 \\
ditr $=2$ & 1.250 & 0.468 & 7.143 & 1 & 0.008 & 0.333 & 2.166 \\
ditr $=3$ & 0.885 & 0.473 & 3.508 & 1 & 0.061 & -0.041 & 1.812 \\
motr $=1$ & 1.858 & 0.594 & 9.772 & 1 & 0.002 & 0.693 & 3.022 \\
motr $=2$ & 0.475 & 0.440 & 1.165 & 1 & 0.280 & -0.387 & 1.337 \\
wkar & 1.794 & 0.276 & 42.242 & 1 & 0.000 & 1.253 & 2.335 \\
fmis & -0.534 & 0.134 & 15.797 & 1 & 0.000 & -0.798 & -0.271 \\
\hline
\end{tabular}

Table 4. Test of parallel lines.

\begin{tabular}{ccc}
\hline Chi-square & df & p-value \\
\hline 6.446 & 9 & 0.695 \\
\hline
\end{tabular}

Table 5. Goodness of fit tests.

\begin{tabular}{cccc}
\hline Test & Chi-square & df & p-value \\
\hline Pearson & 289.873 & 272 & 0.218 \\
Deviance & 202.017 & 272 & 0.999 \\
\hline
\end{tabular}

Table 6. Odds ratios.

\begin{tabular}{cccc}
\hline & Factor & Odds ratio direction & Value \\
\hline gend & Gender & Male to Female & 0.13 \\
ditr & $\begin{array}{c}\text { The distance factory workers travel to } \\
\text { reach the workplace }\end{array}$ & More than $10 \mathrm{~km}$ to Less than $10 \mathrm{~km}$ & 0.49 \\
& $\begin{array}{c}\text { Mode of transportation of factory } \\
\text { workers to reach the workplace }\end{array}$ & Private transportation to Public transportation & 0.51 \\
motr & Public transportation to by walk & 0.34 \\
wkar & Work arrangements in the workplace & A unit increase in the factor & 1.84 \\
fmis & Family issues of the factory workers & A unit increase in the factor & 1.42 \\
\hline
\end{tabular}

ratio of a particular factor was calculated by considering the other factors as constant at their base levels.

According to Odds ratio results, a factory worker who is a male is 0.13 times less likely to be satisfied than a factory worker who is a female. Also a factory worker who travel more than $10 \mathrm{~km}$ to reach the factory is 0.49 times less likely to be satisfied than a factory worker who travel less than $10 \mathrm{~km}$ to reach the factory. A factory worker who uses private transportation to reach the factory is 
0.51 times less likely to be satisfied than a factory worker who uses public transportation to reach the factory. A factory worker who uses public transportation to reach the factory is 0.34 times less likely to be satisfied than a factory worker who reaches the factory by foot. Moreover, the odds of being satisfied increased by a factor of 1.84 as the factor "Work arrangements in the workplace" increased by a unit and the odds of being satisfied increased by a factor of 1.42 as the factor "Family issues of the employees" increased by a unit.

\section{Conclusions}

A questionnaire was used to collect the data in which 54 questions were used to address various aspects of job satisfaction. Among them, 39 questions were based on rating ( 1 - 5 likert scale). The dimension of data was reduced using factor analysis without loss of much information and these factors were defined as Facilitative working environment, Work arrangements, Family issues and Flexible working arrangements.

The overall job satisfaction of the factory workers in the manufacturing plant modeled through the five factors: gender of employees; the distance employees travel to reach the workplace; mode of transportation of employees to reach the workplace; work arrangements in the workplace and family issues of the employees. "Work arrangements in the workplace" is the most important component which leads to the overall job satisfaction of the machine operators compared to the other factors.

Due to the time constraint to carry out the survey process, the scope of this research was limited to identify the job satisfaction level and the factors associated with job satisfaction of the factory workers in the manufacturing plant of a factory. Therefore, the research findings are applicable only to this population under study. Further research can be incorporated with more factory industries representing the whole factory industry in Sri Lanka. Hence, the results can be generalized to the whole factory industry in Sri Lanka.

\section{Conflicts of Interest}

The authors declare no conflicts of interest regarding the publication of this paper.

\section{References}

[1] Locke, E.A. (1976) The Nature and Causes of Job Satisfaction. In: Dunnette, M.D., (Ed.), Handbook of Industrial and Organizational Psychology, Rand McNally, Chicago, 1297-1349.

[2] Hashim, R. and Mahmood, R. (2011) What Is the State of Job Satisfaction among Academic Staff at Malaysian Universities? Unitar E-Journal, 7, 15-26.

[3] Kaliski, B.S. (2007) Encyclopedia of Business and Finance. Second Edition, Thompson Gale, Detroit, 446.

[4] Rice, R.W., Near, J.P. and Hunt, R.J. (1979) Unique Variance in Job and Life Satisfaction Associated with Work Related and Extra Work-Related Variables. Human 
Relations, 32, 605-623. https://doi.org/10.1177/001872677903200706

[5] Kumari, N. (2011) Job Satisfaction of the Employees at the Workplace. European Journal of Business and Management, 3, 4.

[6] Moyes, G.D., Shao, L.P. and Newsome, M. (2008) Comparative Analysis of Employee Job Satisfaction in the Accounting Profession. Journal of Business \& Economics Research, 6, 65-81. https://doi.org/10.19030/jber.v6i2.2392

[7] Spector, P.E. (1997) Job Satisfaction: Application, Assessment, Causes and Consequences. Sage Publications, Inc., Thousand Oaks, 3.

[8] Sweney, P.D. and McFarlin, D.B. (2005) Organizational Behavior, Solutions for Management. McGraw-Hill/Irwin, New York, 57.

[9] Scott, K.D. and Taylor, G.S. (2017) An Examination of Conflicting Findings on the Relationship between Job Satisfaction and Absenteeism: A Meta-Analysis. Academy of Management Journal, 28, 599-612.

[10] Sagie, A. (1998) Employee Absenteeism, Organizational Commitment, and Joba Satisfaction: Another Look. Journal of Vocational Behavior, 52, 156-171. https://doi.org/10.1006/jvbe.1997.1581

[11] Javed, S. and Kamal, A. (2014) Job Satisfaction Factors of PTCL Employees. International Journal of Applied Research, 3, 166-174.

[12] Khatun, R. and Shamsuzzaman, M.D. (2015) Employee's View on Job Satisfaction: A Study on Garment Industry (AKH Group), Bangladesh. International Journal of Research in Management \& Business Studies, 2, 12.

[13] Naing, L., Winn, T. and Rusli, B. (2006) Practical Issues in Calculating the Sample Size for Prevalence Studies. Archives of Orofacial Sciences, 1, 9-14.

[14] Scandura, T.A. and Lankau, M.J. (1997) Relationships of Gender, Family Responsibility and Flexible Work Hours to Organizational Commitment and Job Satisfaction. Journal of Organizational Behavior, 18, 377-391. https://doi.org/10.1002/(SICI)1099-1379(199707)18:4<377::AID-JOB807>3.0.CO;2$\underline{1}$

[15] Clark, A.E. (1997) Job Satisfaction and Gender: Why Are Women So Happy at Work? Labour Economics, 4, 341-372. https://doi.org/10.1016/S0927-5371(97)00010-9

[16] Donohue, S.M. and Heywood, J.S. (2004) Job Satisfaction and Gender: An Expanded Specification from the NLSY. International Journal of Manpower, 25, 211-238. https://doi.org/10.1108/01437720410536007

[17] Hair, J.F., Black, W.C., Babin, B.J. and Anderson, R.E. (2010) Multivariate Data Analysis. 7th Edition.

[18] Kaiser, H.F. (1974) An Index of Factor Simplicity. Psychometrika, 39, 31-36. https://doi.org/10.1007/BF02291575

[19] Yay, M. and Akinci, E.D. (2009) Application of Ordinal Logistic Regression and Artificial Neural Networks in a Study of Student Satisfaction. Cypriot Journal of Educational Sciences, 4, 58-70. 